OPEN ACCESS

Edited by:

Hubert Vaudry,

Université de Rouen, France

Reviewed by:

Xavier Xifró,

University of Girona, Spain

Valerio Magnaghi,

University of Milan, Italy

*Correspondence:

Cheryl A. Frye

cheryl.a.frye@gmail.com

Specialty section:

This article was submitted to

Neuroendocrine Science,

a section of the journal

Frontiers in Endocrinology

Received: 17 April 2020 Accepted: 02 September 2020

Published: 11 January 2021

Citation:

Frye CA, Lembo VF and Walf AA (2021) Progesterone's Effects on Cognitive Performance of Male Mice

Are Independent of Progestin Receptors but Relate to Increases in $G A B A_{A}$ Activity in the Hippocampus and Cortex.

Front. Endocrinol. 11:552805. doi: 10.3389/fendo.2020.552805

\section{Progesterone's Effects on Cognitive Performance of Male Mice Are Independent of Progestin Receptors but Relate to Increases in $\mathrm{GABA}_{A}$ Activity in the Hippocampus and Cortex}

\author{
Cheryl A. Frye ${ }^{1,2,3,4,5,6,7,8 *}$, Vincent F. Lembo ${ }^{8}$ and Alicia A. Walf ${ }^{1,5,7,9}$ \\ ${ }^{1}$ Department of Psychology, The University at Albany-SUNY, Life Sciences, Albany, NY, United States, ${ }^{2}$ Department of \\ Biological Sciences, The University at Albany-SUNY, Life Sciences, Albany, NY, United States, ${ }^{3}$ The Center for Neuroscience \\ Research, The University at Albany-SUNY, Life Sciences, Albany, NY, United States, ${ }^{4}$ The Center for Life Sciences Research, \\ The University at Albany-SUNY, Life Sciences, Albany, NY, United States, ${ }^{5}$ Institute of Arctic Biology, University of \\ Alaska-Fairbanks, Fairbanks, AK, United States, ${ }^{6}$ Department of Chemistry, University of Alaska-Fairbanks, Fairbanks, AK, \\ United States, ${ }^{7}$ IDeA Network of Biomedical Excellence (INBRE), University of Alaska-Fairbanks, Fairbanks, AK, \\ United States, ${ }^{8}$ Comprehensive Neuropsychological Services, Albany, NY, United States, ${ }^{9}$ Department of Cognitive Science, \\ Rensselaer Polytechnic Institute, Troy, NY, United States
}

Progestogens' (e.g., progesterone and its neuroactive metabolite, allopregnanolone), cognitive effects and mechanisms among males are not well-understood. We hypothesized if progestogen's effects on cognitive performance are through its metabolite allopregnanolone, and not actions via binding to traditional progestin receptors (PRs), then progesterone administration would enhance performance in tasks mediated by the hippocampus and cortex, coincident with increasing allopregnanolone concentrations, brain derived neurotrophic factor (BDNF) and/or muscimol binding of PR knock out (PRKO) and wild-type PR replete mice. Experiment 1: Progesterone (4 mg/kg, subcutaneously (SC; $n=12 / \mathrm{grp}$ ), or oil vehicle control, was administered to gonadally-intact adult male mice PRKO mice and their wild-type counterparts and cognitive behaviors in object recognition, T-maze and water maze was examined. Progesterone, compared to vehicle, when administered post-training increased time investigating novel objects by the PRKO and wild-type mice in the object recognition task. In the T-maze task, progesterone administration to wild-type and PRKO mice had significantly greater number of spontaneous alternations compared to their vehicle-administered counterparts. In the water maze task, PRKO mice administered vehicle spent significantly fewer seconds in the quadrant associated with the escape platform on testing compared to all other groups. Experiment 2: Progesterone administered to wild-type and PRKO mice increased plasma progesterone and allopregnanolone levels ( $n=5$ /group). PRKO mice had higher allopregnanolone levels in plasma and hippocampus, but not cortex, when administered progesterone and 
compared to wild-type mice. Experiment 3: Assessment of PR binding revealed progesterone administered wild-type mice had significantly greater levels of PRs in the hippocampus and cortex, compared to all other groups ( $n=5 /$ group). Wild-type mice administered progesterone, but not vehicle, had increased BDNF levels in the hippocampus, but not the cortex, compared to PRKOs. Wild-type as well as PRKO mice

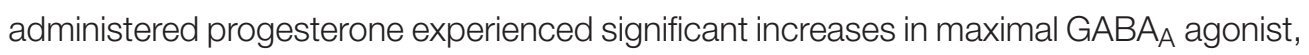
muscimol, binding in hippocampus and cortex, compared to their vehicle-administered counterparts. Thus, adult male mice can be responsive to progesterone for cognitive performance, and such effects may be independent of PRs trophic actions of BDNF levels in the hippocampus and/or increases in $\mathrm{GABA}_{\mathrm{A}}$ activity in the hippocampus and cortex.

Keywords: brain-derived neurotrophic factor, prefrontal cortex, allopregnanolone, hippocampus, object recognition, T-maze, memory

\section{INTRODUCTION}

Our understanding of progesterone, a gonadal hormone that is produced primarily by the ovaries in females, as well as progestin receptors (PRs) functioning, has primarily come from studies in females (1-3). Although progesterone has always been considered a "female-typical hormone," adult male rodents produce progesterone in the testes and adrenal cortex $(4,5)$. Male rodents have circulating levels of progesterone around $1.5-2 \mathrm{ng} / \mathrm{mL}(6,7)$, compared to a range of $3-35 \mathrm{ng} / \mathrm{mL}$ in females that is seen throughout the estrous cycle (8). Males, compared to females, have higher levels of steroid receptor co-activators, which enhance steroid hormone action in many brain regions (9). Of note, across species, both males and females have early exposure to maternal progesterone, by which brain functioning is organized. "Male-typical" hormones, such as androgens are derived from a cholesterol-based pro-hormone, progesterone. Thus, despite conceptualization of progesterone as a female hormone, the extent to which adult males respond to progesterone is an important question.

Progesterone can exert beneficial effects for cognitive performance; however, most of the work on progesterone's cognitive effects has involved female subjects. Compared to other treatments, progesterone to rodents assessed in the Morris water maze reduced latencies to the hidden platform, increased platform crossings, and time spent swimming in the quadrant area where the platform had been during training (10). Progesterone improved reference memory acquisition and reversal learning in the Morris water maze task, compared with vehicle treatment (11). In addition, young and aged rodents administered progesterone, or its neuroactive metabolite, allopregnanolone, performed significantly better in the object recognition, object placement, T-maze, and water maze tasks compared to other groups $(12,13)$. Progesterone can have memory-enhancing effects among young adult mice in condition place preference, inhibitory avoidance and other tasks that may be mediated by several brain regions, including the hippocampus, prefrontal cortex (PFC), amygdala, nucleus accumbens, and cerebellum $(14,15)$. Thus, progesterone has beneficial effects to improve cognitive performance of female rodents across a variety of tasks. The question remains about the responsiveness of males to progesterone on cognitive performance.

To understand the role and brain targets of progestogens for cognitive performance among males, different mechanisms of actions of progesterone and its metabolic allopregnanolone should be considered. Unlike allopregnanolone, progesterone binds with high affinity to intracellular PRs (16). Progestin receptors have been localized to brain targets for learning/memory effects of progesterone in the hippocampus (17) and the frontal cortex (18). However, progesterone may be exerting its effects through its metabolite, allopregnanolone, which has greater affinity for $\gamma$-aminobutyric acid $\left(\mathrm{GABA}_{\mathrm{A}}\right)$ receptors. Allopregnanolone alters functioning of many neurotransmitter targets, rather than binding to PRs, when in physiological concentrations (19-21). Female mice, administered allopregnanolone or those that were administered progesterone and could metabolize this to allopregnanolone, performed significantly better in the object recognition, object placement, T-maze and water maze tasks compared to female mice administered vehicle (12). In addition, rodents administered allopregnanolone, perform better in the water maze, a delayed nonmatching-to-sample Y-maze task, object recognition and object placement tasks, and conditioned aversion tasks and have enhanced conditioned place preference compared to controls (22-27). Moreover, PR knockout (PRKO) mice, which lack PRs throughout development (28), have been used. For example, young and/or aged PRKO and wild-type mice have increased sexual responding, decreased anxiety-like behavior, and enhanced cognition following progesterone administration, despite PRKO mice having low levels of cortical PR binding (29, 30). Cognitive enhancement among both PRKO and wild-type mice administered progesterone suggests that PRs are not necessary for progesterone's beneficial effects on cognitive performance. Thus, progesterone's beneficial effects across various cognitive tasks may be related to the capacity to produce allopregnanolone, rather than actions at PRs among females. Of interest is the effects among males.

Another non-PR target to be considered is brain-derived neurotrophic factor (BDNF). BDNF is produced both in neurons and glial cells $(31,32)$. BDNF is of interest as a marker of 
neural plasticity, which may play a role in synaptic plasticity and learning/memory $(33,34)$. There is strong evidence to support the role of BDNF in synaptic plasticity and cognitive function (35) and as such, alterations in its function and/or expression have been implicated in the pathophysiology of aged-related neurodegenerative diseases including Alzheimer's disease, Parkinson's disease, seizure disorder, major depression (34, 36-45), and a variety of stressors/events [e.g., ischemia, hypoglycemia, stressor exposure, etc. $(46,47)]$. Restoring BDNF expression and/or function may be therapeutic. Furthermore, there is evidence that progesterone and other hormones have enhancing effects on BDNF expression. BDNF levels are increased and are associated with administration of progesterone and/or cognitive enhancement (12, 33, 34, 48-53). Thus, BDNF may play a role for cognitive enhancement following progesterone administration.

An important question is the responsiveness of progesterone in a mouse model that should be less sensitive to progesterone effects (adult males, low levels of progesterone, and no PRs). Notably, young males in some cases do not respond to progesterone as females do. For example, duration spent immobile in the forced swim task is not reduced with progesterone administration in young males to the same extent that it is in age-matched females; this sex difference is no longer apparent in aged mice (54). We hypothesized if progesterone's effects on learning/memory are through its metabolite allopregnanolone, and not due to traditional actions via binding to $\mathrm{PRs}$, progesterone administration posttraining will enhance performance in tasks mediated by the hippocampus and cortex, coincident with increasing allopregnanolone concentrations in the hippocampus and cortex, and increase $\mathrm{BDNF}$ levels or activity of $\mathrm{GABA}_{\mathrm{A}}$ receptors of both PRKO and wildtype mice. To test this, gonadally-intact male wild-type and PRKO mice were administered progesterone and/or oil vehicle and exp 1: cognitive behaviors (object recognition, T-maze and Water maze), exp 2: neuroendocrine factors (plasma, hippocampal and cortical progesterone and allopregnanolone levels), and trophic factors, $\mathrm{PR}$ binding, BDNF levels in the hippocampus and cortex, and $\mathrm{GABA}_{\mathrm{A}}$ activity in the hippocampus and cortex were assessed.

\section{METHODS AND MATERIALS}

The methods utilized for animal husbandry, determination of WT vs. PRKOs, drug administration, behavioral testing, euthanasia and tissue collection in the murine subjects in this study were approved by the Institutional Animal Care and Use Committee at the University at Albany.

\section{Animal Housing}

Subjects were adult (8-10 weeks old), male mice. Mice were group-housed (4-5 per cage) in polycarbonate cages $(26 \times 16$ $\times 12 \mathrm{~cm})$ in a temperature-controlled room $\left(21 \pm 1^{\circ} \mathrm{C}\right)$ in the core Laboratory Animal Care Facility at the University at Albany. The housing room was on a 12/12-h reversed light cycle (lights off 8:00 a.m.-8:00 p.m.). Mice had continuous access to Purina Mouse Chow and tap water in their home cages and were assessed during their dark phase. There were 50/12-13 mice group in one cohort and 20/5 mice group in another cohort. The first cohort of 5 per group was done to examine physiological measure around 15 generations of back crossings to bring the PRKO mice from their 129 background strain onto the c57UA strain, which were c57 mice that had been subjected to random and frequent fire alarms with changes in air pressure for 4 years.

\section{Mouse Strain and Genotyping}

PRKO mice that were back crossed onto a c57 background are not distinguishable based upon any obvious phenotypic or behavioral characteristics from c57 controls. As such, another member of the laboratory conducted genotyping, as described below, and randomly assigned them to groups, which were unknown to the individuals that were testing the animals. Subjects were wild-type $(+/+)$ or (-/-) PRKO mice, congenic on C57BL/6 background, that were derived from heterozygous $(+/-)$ breeder pairs from a colony that was maintained at the University at Albany. These mice were developed by Bert O'Malley's laboratory [Baylor College of Medicine, Houston, Texas; $(29,55)]$. Typical polymerase chain reaction (PCR) methods, modified from Jackson Laboratory's published protocol, were utilized to determine the genotype of mice $(54,56)$. Briefly, genomic DNA was isolated from tail snips and analyzed by PCR. PCR was performed by denaturing the DNA at $95^{\circ} \mathrm{C}$ for $5 \mathrm{~min}$, followed by 30 cycles of amplification: $94^{\circ} \mathrm{C}$ for $1 \mathrm{~min}$, $60^{\circ} \mathrm{C}$ for $1 \mathrm{~min}, 72^{\circ} \mathrm{C}$ for $1 \mathrm{~min}$, and a final primer extension step at $72^{\circ} \mathrm{C}$ for $10 \mathrm{~min}$. The following PR specific primers were used: P1 (5'TAGACAGTGTCTTAGACTCGTTGTTG-3'), P2 (5'GATGGGCACATGGATGAAATC- $3^{\prime}$ ), and a neo gene specific primer, N2 (5'GCATGCTCCAGACTGCCTTGGGAAA$\left.3^{\prime}\right)$. Primers were obtained from Integrated DNA Technologies (Coralville, IA). Bands of $\sim 565$ and 500 base pairs were amplified for wild-type and PRKO mice, respectively. PRKO and wildtype mice were randomly assigned to receive progesterone or vehicle as described below. The individual who was testing the animals was blind to the genotype of all animals and the vehicle or progesterone administration condition.

\section{Progesterone Administration}

Crystalline progesterone was obtained from Steraloids, Newport, $\mathrm{RI}$ and dissolved in vegetable oil vehicle. Intact male mice were randomly assigned to receive progesterone $(4 \mathrm{mg} / \mathrm{kg})$ or vehicle (vegetable oil) by subcutaneous injection (SC) in the nape of the neck $1 \mathrm{~h}$ before behavioral testing in the T-maze, immediately after training in the single trial of the object recognition task, and after the last training trial in the water maze (57).

\section{Behavioral Testing}

Wild-type and PRKO mice were assigned to one hormone condition (vehicle or progesterone) and then, tested once per week in each of the behavioral tasks described below. Behavioral data were collected simultaneously by an experimenter (T-maze), the Any-Maze tracking system (Stoelting, Wood Dale, IL; object recognition), and/or both methods (water maze). On the day when mice were trained and tested, they were transported in 
their home-cages on a cart to the testing area. Mice were singlyhoused in a clean cage immediately before training and until the last testing trial, when they were returned to their home-cage in the vivarium.

\section{Object Recognition}

In the object recognition task, mice were trained with two identical objects, i.e., a plastic toy block or a bottle, that were placed in an open field. The objects used were those that mice showed a high and similar degree of investigating during a single, $3 \mathrm{~min}$ training trial (58). There were no significant differences between genotypes or treatment group for time spent investigating objects during training in the object recognition task [left object: WT: $12.1 \pm 2.2 \mathrm{~s}$ (SEM), PRKO: $10.2 \pm 1.4 \mathrm{~s}$ (SEM); right object: WT: $11.1 \pm 1.9 \mathrm{~s}$ (SEM), PRKO: $11.9 \pm 2.3 \mathrm{~s}$ (SEM); training data are from mice that were trained before receiving treatment]. The durations spent within $5 \mathrm{~cm}$ of the object, directly in contact, investigating and/or orienting toward the objects were automatically recorded using Any-Maze for the training and testing trials. Immediately after training, mice were injected with vehicle and/or progesterone. Mice were tested in this task $4 \mathrm{~h}$ after training. During testing, there was a novel object and a familiar object (i.e., the object that mice had been trained with) and mice freely explored in the testing chamber for $3 \mathrm{~min}$. The duration of time the mice spent exploring the familiar and novel objects were recorded.

\section{T-maze}

Spontaneous alternation was assessed in the T-maze, which has a clear Plexiglas start box connected to a start arm $(30.5 \times 9 \times$ $7 \mathrm{~cm})$ and two goal arms $(17.8 \times 9 \times 7 \mathrm{~cm})$. Mice were placed in the start box $1 \mathrm{~h}$ after vehicle or progesterone treatment. The door was opened and following one forced trial (where either the left or right side was blocked in a random fashion), the number of spontaneous alternations made to each goal arm was assessed for 13 consecutive trials $(\max$ latency $=900 \mathrm{~s}$ ). Each of the 13 trials consisted of the mouse fully returning to the start arm and then, entering the right or left goal arm $(13,59)$. Data were handcollected by an experimenter and videos of trials were recorded using Any-Maze or a video-camera. The index of performance in this task is the number of successful alternating trials out of 13 possible trials.

\section{Water Maze}

The water maze was filled with $25^{\circ} \mathrm{C}$ tap water and was made opaque by the addition of white non-toxic tempera paint. Mice were habituated to the maze by allowing them to swim in the water maze with the hidden platform $(8 \times 8 \mathrm{~cm})$ in it. After $1 \mathrm{~min}$, mice were placed on the hidden platform for $10 \mathrm{~s}$. Following habituation, mice were trained in twelve 1-min trials which were organized into 3 blocks of 4 trials with a randomized starting position in the maze represented during each of these 4 trials in the block. There were 3 different starting positions in the maze. In each trial, mice had $60 \mathrm{~s}$ to find the clear platform in the opaque water (hidden platform). Latencies to find the platform and distance traveled were recorded simultaneously by the experimenter and the Any-Maze tracking program. Each block of trials had a 30 min inter-trial interval. Mice were injected with vehicle or progesterone immediately after the last training trial. Before the probe trial to assess spatial memory, the hidden platform was removed from the water maze. Thirty minutes following vehicle or progesterone administration, mice were returned to the water maze at a random position. The latency to return to the quadrant that had the platform, and the duration of time spent in that quadrant, were the indices of cognitive performance in this task. Immediately after the probe trial, mice were tested in a cued trial of the water maze to assess their ability to swim to a platform in the maze. During this trial, the latency of mice to swim to a platform that is made visible and cued is determined to rule out the ability to perform the task $(13,30)$. There were no differences between groups in these measures (data not shown).

\section{Tissue Collection}

Immediately after testing in the water maze, mice were euthanized by cervical subluxation and decapitation. Whole brains were collected from mice and stored frozen at $-70^{\circ} \mathrm{C}$ until brain regions were processed for enzyme-linked immunosorbent assays (ELISA), progesterone, allopregnanolone, BDNF, PR binding and muscimol binding. The cortex and hippocampus were grossly dissected from the whole brain on ice prior to steroid and BDNF measurement.

\section{Sample Preparation}

The cortex and hippocampus were dissected out and homogenized with a pestle in 500 microliters of distilled water in a microcentrifuge tube and centrifuged for $10 \mathrm{~min}$ at $3,000 \mathrm{x}$ g. Protein concentrations in each sample were measured using a Nanodrop Spectrometer (Thermo Scientific, Federal Way, WA).

\section{Allopregnanolone, Progesterone and BDNF ELISAs}

Analyses of allopregnanolone and progesterone were per standard methods of the ELISA kits purchased from Arbor Assays (Ann Arbor, MI). Fifty microliters of homogenized sample were added to each well.

Analyses of BDNF were per standard methods of the Emax Immunoassay system [Promega, Fisher Scientifics; (12, 60, 61)]. Brain homogenates were homogenized in 10 microliters of cell lysis buffer (Qiagen) with a pestle in a microcentifuge tube. Fifty microliters of these prepared homogenates were diluted in 4 volumes of Dulbecco's Phosphate-Buffered Saline (Fisher Scientific). Diluted samples were acid-treated by adding 1 microliter of $1 \mathrm{~N} \mathrm{HCl}$, incubating for $15 \mathrm{~min}$ at room temperature, and then neutralizing the samples by adding 1 microliter of $1 \mathrm{~N} \mathrm{NaOH}$.

For allopregnanolone, progesterone and BDNF ELISA, 50 microliters of prepared Detection Reagent A was immediately pipetted into wells. Plates were shaken, mixed and incubated for $1 \mathrm{~h}$ at $37^{\circ} \mathrm{C}$. Samples were then aspirated and washed 3 times with 350 microliters of $1 \mathrm{x}$ wash buffer. Any remaining liquid from all wells was removed completely by snapping the plate onto absorbent paper. Next, 100 microliters of prepared 
Detection Reagent B was pipetted into each well and incubated for $30 \mathrm{~min}$ at $37^{\circ} \mathrm{C}$. Plate was then aspirated and washed 5 times with 350 microliters of $1 \mathrm{x}$ wash buffer and any remaining liquid was removed from wells by snapping the plate onto absorbent paper. Then, 90 microliters of substrate solution was pipetted into each well and incubated for $15-25 \mathrm{~min}$ at $37^{\circ} \mathrm{C}$ and placed in the dark where the liquid turned blue. Lastly, 50 microliters of stop solution was pipetted into each well and gently tapped. The addition of the stop solution turned the liquid yellow. Immediately after, the plate was read at $450 \mathrm{~nm}$ on a microplate reader (Bio-tek, Thermo Scientific, Federal Way, WA).

\section{Progestin Receptor Binding}

Progestin receptors in hippocampus and cortex were investigated in $n=5$ mice per group to confirm that backcrossing PRKOs to make them congenic on our c57UA strain did not alter their brain levels of progestin receptors. We used the tritiated synthetic competitive binding assay as previously described (54, 55) with RU5020 (promegestrone; 17 $\alpha$, 21-dimethyl-19nor-pregna-4,9-diene-3,20-dione), which has a $\mathrm{Kd}$ of $0.4 \mathrm{nM}$ for progestin receptors (62). Progestin receptors are found in pituitary, reproductive tract and most estrogen receptorcontaining brain regions (62). There are also progestin receptor sites in brain areas lacking estrogen receptors, such as the cerebral cortex, which are similar to those induced by estradiol.

\section{Muscimol Binding}

As per our previous methods (63), tissues were thawed and resuspended in $0.05 \mathrm{M}$ Tris- $\mathrm{HC} 1$ buffer to a protein concentration of $0.8 \mathrm{mg}$ protein per tube in a final volume of $0.5 \mathrm{ml}$. [ ${ }^{3} \mathrm{H}$ ] muscimol (NET 574, spec. act. $14.72 \mathrm{Ci} / \mathrm{mmol}$, New England Nuclear, Boston, MA, USA) at $10-100 \mathrm{nM}$ concentrations was added and incubation was continued at $4^{\circ} \mathrm{C}$ for $30 \mathrm{~min}$. Non-specific binding was determined by addition of $1 \mathrm{mM}$ cold GABA as a displacer of bound [3H] muscimol. The bound and free fractions were separated by vacuum filtration through GF/C glass filters and washed twice very quickly with $0.05 \mathrm{M}$ Tris buffer [89]. Filters were placed in scintillation vials to dry overnight. The next day, scintillation cocktail was added and the vials were counted for radioactivity and degradations per minute were calculated. The $\mathrm{E}_{\max }$ of specific muscimol binding was used as the variable of interest.

\section{Statistical Analyses}

For all measures except the T-maze task, two-way ANOVAs were used to determine effects of hormone condition (vehicle or progesterone) and genotype (wild-type or PRKO). Two subjects were removed from the main cohort, as they varied more than 2 standard deviations from the mean in their group. One subject was from the wild-type progesterone group and the other was from the wild-type prko group. This resulted in an equal number of observations across groups ( $n=12$ /group) and no question as to the adherence of the assumptions of the premises of the ANOVAs. A $X^{2}$-square test of independence with Yates correction was performed to examine the relationship between progesterone and genotype and the ability to alternate in the $\mathrm{T}$ maze. The $\alpha$ level for statistical significance was $p \leq 0.05$. Fisher's post-hoc tests were used to examine group differences.

\section{RESULTS}

\section{Progesterone to PRKO and Wild-Type Male Mice Enhances Object Recognition}

Progesterone administered mice spent significantly more time with the novel object during testing in the object recognition task. Wild-type and PRKO mice administered progesterone spent more time spent with the novel object compared to their vehicle administered counterparts $\left[\left(\mathrm{F}_{(1,44)}=22.88, P<0.001\right)\right.$ see Figure 1, top]. There were neither effects of genotype, nor significant interactions of genotype and progesterone, for time spent with the novel object during testing.

\section{Progesterone to PRKO and Wild-Type Male Mice Results in More Spontaneous Alternation in the T-maze Task}

A chi-square test of independence was performed to examine the relationship between progesterone and genotype and the ability to alternate in the $T$ maze. The relationship between these variables was significant, according to $X^{2}$ with Yates correction (4, $N=48)=8.9, p=0.02$. Mice, irrespective of wild type or PRKO, administered progesterone made significantly greater number of alternations in the T-maze than did vehicle-administered mice. Indeed, progesterone administered mice made approximately twice the number of spontaneous alternations than did their vehicle-administered counterparts. See Figure 1, middle.

\section{Progesterone to PRKO and Wild-Type Male Mice in the Water Maze Task}

Hormone condition and genotype interacted, such that PRKO, vehicle-administered mice had longer latencies to find the quadrant where the platform had been, compared to all other groups $\left[\mathrm{F}_{(3,44)}=22.87, P<0.0001\right]$. Progesterone and genotype also interacted in that PRKO, vehicle-administered mice, spent less time in the quandrant where the platform had been located compared to all other groups $\left[\mathrm{F}_{(3,44)}=13.56, P<0.0001\right]$ See Figure 1, bottom. There were no significant differences for the time spent in the quadrant of the hidden platform during the probe trial and the latency to find the platform in the cued trial indicating initial performance variables were not a factor (data not shown).

\section{Progesterone Increased Plasma Progestogens in PRKO > Wild-Type Male Mice}

Progesterone condition and genotype significantly interacted to influence circulating plasma progesterone $\left[\mathrm{F}_{(1,16)}=69.77\right.$, $P<0.0001]$ and allopregnanolone $\left[F_{(1,16)}=28.59, P<\right.$ $0.0001]$. PRKO mice administered progesterone had significantly higher circulating progesterone (see Figure 2, top left) and allopregnanolone (see Figure 2, top right) levels compared to all other groups. 


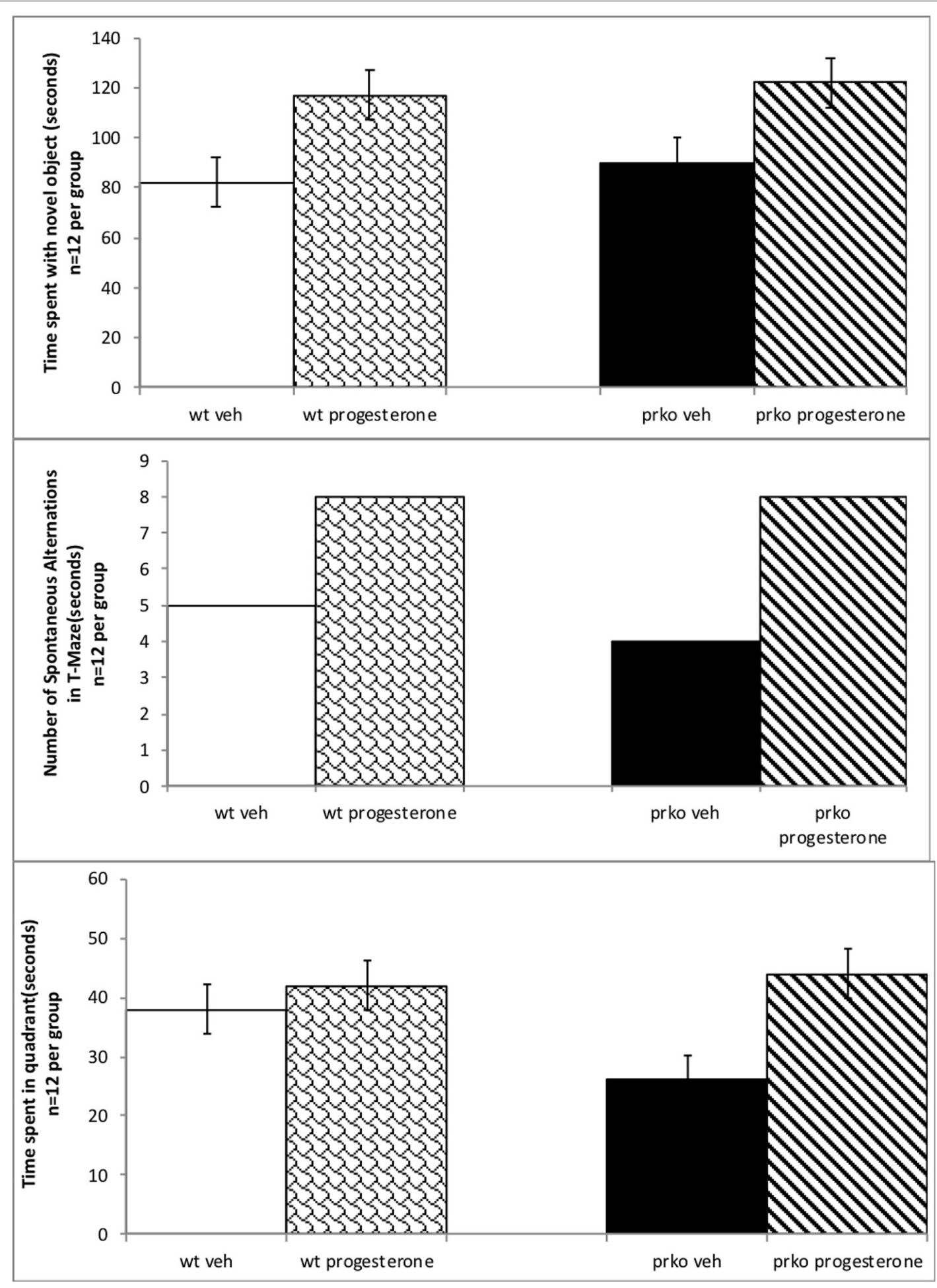

FIGURE 1 | Results from the vehicle wildtype mice are represented by white bars, $\mathrm{P}_{4}$ wildtype by stippled bars, vehicle PRKO by black bars, and $\mathrm{P}_{4}$ PRKO mice are represented by diagonally striped bars. There are 12 animals per experimental group. The top panel represents mean time (in secs) spent with novel object ( \pm S.E.M.) Wildtype or PRKO male mice administered $\mathrm{P}_{4}$ had enhanced cognitive performance in the object recognition task compared to vehicle administration among wild-type and PRKO mice. The middle panel indicates the mean number of spontaneous alternations ( \pm S.E.M.) in the T-maze out of 13 trials. Wildtype or PRKO male mice administered $\mathrm{P}_{4}$ had ac greater number of spontaneous alterations in the T-maze compared to vehicle administered groups. The bottom panel represents the mean number of seconds spent in the quadrant ( \pm S.E.M.) where the hidden platform had been in previous trials. PRKO vehicle mice spent significantly less time in the quadrant than did all other groups. 


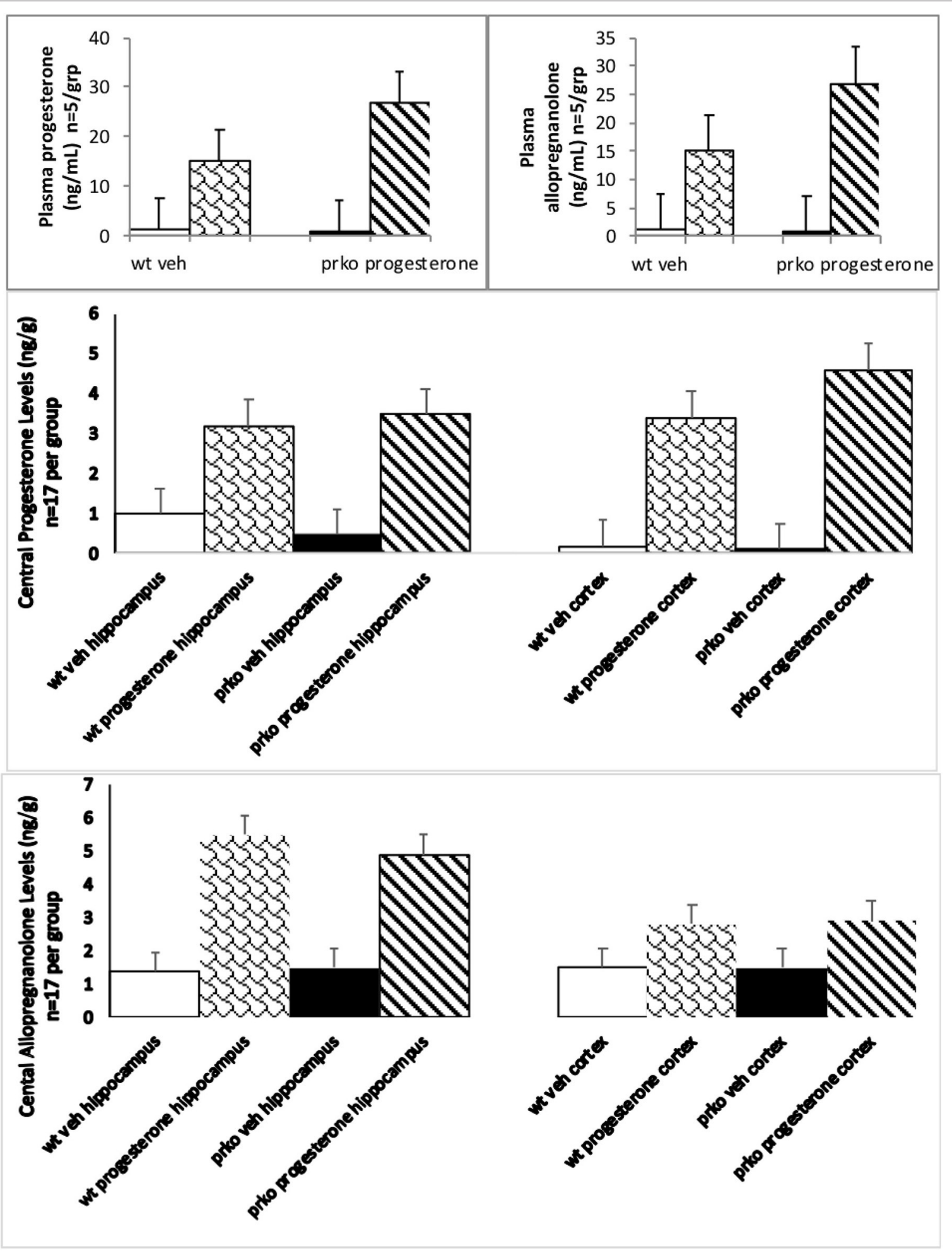

FIGURE 2 | The results from the vehicle wildtype mice are represented by white bars, $\mathrm{P}_{4}$ wildtype by stippled bars, vehicle PRKO by black bars, and $\mathrm{P}_{4}$ PRKO mice are represented by diagonally striped bars. The top left panel represents plasma progesterone levels $(n=5 / g r o u p)$ whereas the top right panel represents plasma allopregnanolone levels ( $n=5 /$ group). Progesterone administration significantly increased progesterone and allopregnanolone levels for PRKO > wild-type male mice. The middle panel represents central levels of progesterone in the hippocampus left side and cortex right side ( $n=17 /$ this and all other brain groups). The bottom panel represents central levels of allopregnanolone in the hippocampus left side and cortex right side ( $n=17 / g r o u p)$. Progesterone administration significantly increased hippocampal and cortical progesterone and allopregnanolone levels for both wild-type and PRKO male mice. 


\section{Progesterone and Genotype Interacted With Progestogens in Cortex Not Hippocampus}

Progesterone $\left[\mathrm{F}_{(1,64)}=405.86, P<0.01\right]$ and genotype $\left[\mathrm{F}_{(1,64)}\right.$ $=5.27, P<0.05]$ conditions significantly influenced hippocampal levels of progesterone. Progesterone administration produced hippocampal levels of progesterone around $3.25 \mathrm{ng} / \mathrm{g}$ compared to vehicle $0.58 \mathrm{ng} / \mathrm{g}$. PRKOs had mean levels of progesterone around $2.1 \mathrm{ng} / \mathrm{g}$ compared to wild-types $1.8 \mathrm{ng} / \mathrm{g}$ (see Figure 2, middle right).

Progesterone condition and genotype significantly interacted to influence cortical progesterone levels $\left[\mathrm{F}_{(1,64)}=4.80, P<\right.$ $0.03]$. PRKO mice had significantly higher levels of progesterone in the cortex (see Figure 2, middle left) compared to all other groups.

\section{Progesterone Has Effects Irrespective of Genotype to Alter Central Allopregnanolone}

Progesterone $\left[F_{(1,64)}=202.10, P<0.0001\right]$ condition significantly influenced hippocampal levels of allopregnanolone. Progesterone administration produced hippocampal levels of allopregnanolone around $5.2 \mathrm{ng} / \mathrm{g}$ compared to vehicle $1.4 \mathrm{ng} / \mathrm{g}$ (see Figure 2, bottom left).

Progesterone $\left[F_{(1,64)}=80.67, P<0.0001\right]$ condition significantly influenced cortical levels of allopregnanolone. Progesterone administration produced cortical levels of allopregnanolone around $2.6 \mathrm{ng} / \mathrm{g}$ compared to vehicle $1.3 \mathrm{ng} / \mathrm{g}$ (see Figure 2, bottom right).

\section{Progesterone Increased Progestin Receptor Binding Sites in Hippocampus and Cortex Cortex of Wild-Type but Not PRKO Male Mice}

Progesterone condition significantly interacted with genotype to influence $\left[{ }^{3} \mathrm{H}\right]$ RU5020 Emax moles/g in the hippocampus [F $(1,16)=12.14, P<0.001]$. Progesterone administration produced increased PR binding to $\sim 3.5 \mathrm{moles} / \mathrm{g}$ compared to all other groups, which averaged 1.7 (see Figure 3, top left).

Progesterone condition significantly interacted with genotype to influence $\left[{ }^{3} \mathrm{H}\right]$ RU5020 Emax N/g in the cortex $\left[\mathrm{F}_{(1,16)}\right.$ $=252.11, P<0.0001]$. Progesterone administration increased PR binding to $\sim 4.3$ moles/g among wild-types compared to all other groups, which averaged 2.2 (see Figure 3, top right).

\section{Progesterone Increased BDNF Levels in Hippocampus but Not Cortex of PRKO and Wild-Type Male Mice}

There was a significant main effect of progesterone to increase BDNF levels in the hippocampus [ $\mathrm{F}_{(1,46)}=4.70, P<0.008$ ] irrespective of genotype (see Figure 3, middle left).

Progesterone, compared to vehicle administration, increased BDNF levels in the hippocampus. There was neither an effect of genotype, nor an interaction between genotype and hormone condition. These effects were not observed in the cortex (see Figure 3, middle right).

\section{Progesterone Increased E max Muscimol Binding in Cortex of PRKO and Wild-Type Male Mice}

Progesterone administration significantly enhanced maximal ${ }^{3} \mathrm{H}$ muscimol binding in the hippocampus irrespective of genotype $\left[F_{(1,16)}=2,030.41, P=0.0001\right]$. See Figure 3, left. There was no difference between muscimol binding of wild-type and PRKO mice.

Progesterone administration significantly enhanced maximal ${ }^{3} \mathrm{H}$ muscimol binding in the cortex irrespective of genotype $\left[F_{(1,16)}=2,202.02, P=0.0001\right]$. See Figure 3, right. There was no difference between muscimol binding of wild-type and PRKO mice.

\section{DISCUSSION}

This study generally supports our a priori hypothesis that progesterone, compared to vehicle, to male PRKO and wildtype mice could improve cognitive performance. In the water maze task, wild-type mice tended to outperform PRKO mice, where wild-type mice had shorter latencies to find the hidden platform compared to PRKO mice. However, in the object recognition and T-maze tasks, progesterone improved performance in both the PRKO and wild-type mice. Progesterone administered to wild-type and PRKO mice higher progesterone levels in the hippocampus and cortex. On the contrary, PRKO mice had higher allopregnanolone in the hippocampus and cortex compared to wild-type mice. Moreover, wild-type, but not PRKO, mice had higher BDNF levels in the hippocampus with progesterone administration compared to vehicle administration. No differences were seen in the cortex for progesterone to increase BDNF levels. Yet, muscimol binding in cortex was similarly increased in wt and PRKO mice administered progesterone. Thus, progesterone's actions in wild-type and PRKO male mice to enhance cognitive performance may be associated with allopregnanolone and/or $\mathrm{BDNF}$ expression, in the hippocampus, or cortical increases in allopregnanolone and $\mathrm{GABA}_{\mathrm{A}}$ activity.

In the present study, progesterone improved cognitive performance in the object recognition and T-maze task among wild-type and PRKO mice. This finding extends previous published data. Progesterone treatment immediately posttraining enhances object recognition in young (14), middle-aged, and aged (64) mice. Also, progesterone administration to young and/or aged mice improved cognitive performance in these tasks $(13,60)$. However, in the water maze task, wild-type mice tended to outperform PRKO mice. There are beneficial effects of post-training progesterone on spatial memory consolidation in the Morris water maze in mice (64). In addition, it has been previously observed that aged wild-type mice outperform PRKO mice (57). Although, PRKO mice have reduced levels of PR binding $(65,66)$, there are significant increases in cognitive behavior of progesterone administered PRKO and wild-type mice 


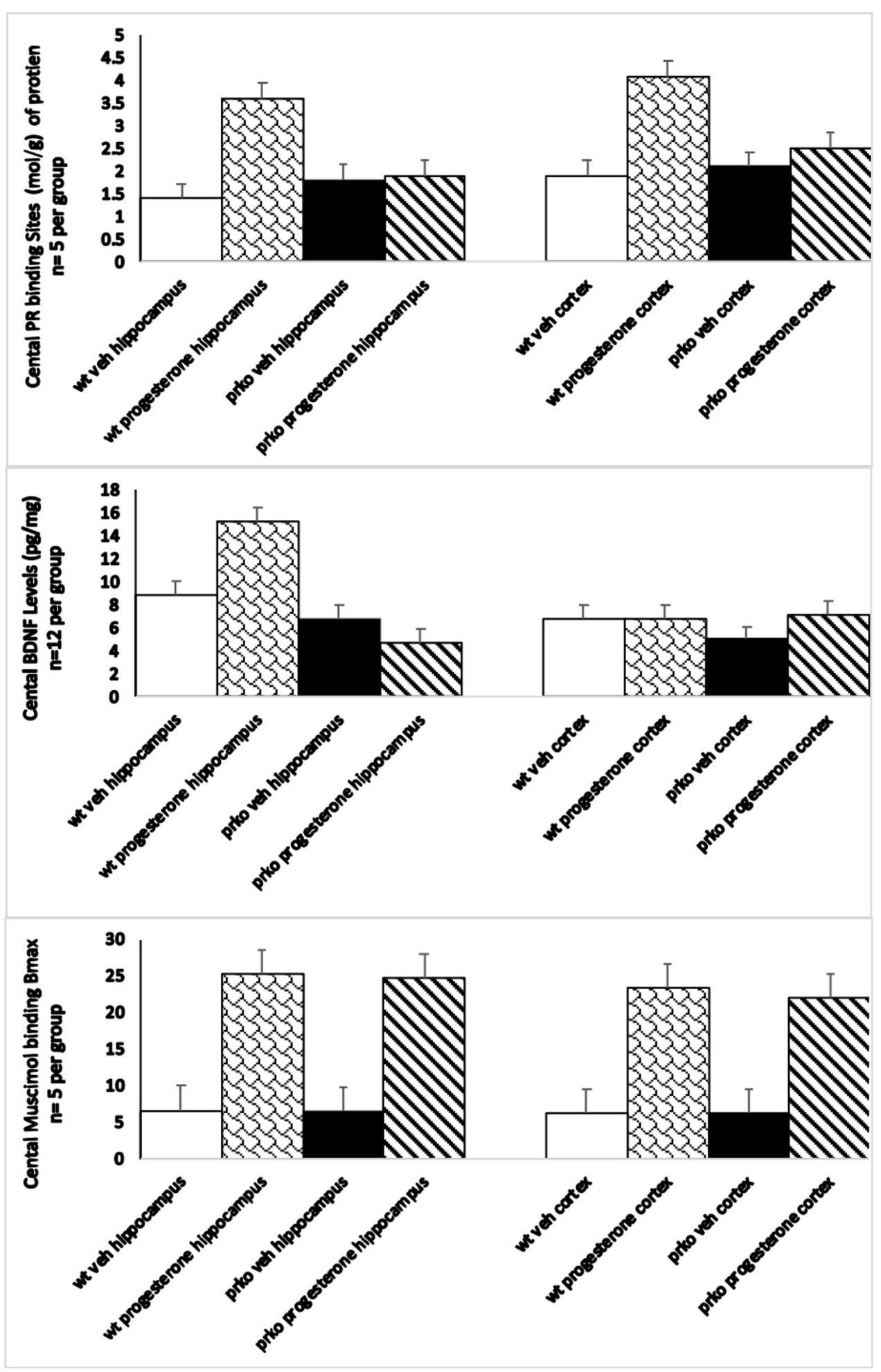

FIGURE 3 | The vehicle wildtype mice results are represented by white bars, $\mathrm{P}_{4}$ wildtype by stippled bars, vehicle PRKO by black bars, and $\mathrm{P}_{4}$ PRKO mice are represented by diagonally striped bars. The top panel represents $\mathrm{E}_{\max }$ progestin receptor binding $(n=5 / \mathrm{group})$ in the hippocampus in the left panel, and cortex in the right panel. Only wild-type mice administered progesterone showed significant increases in progestin receptor binding. The middle panel represents BDNF levels $(n$ $=12$ /group) in the hippocampus in the left panel, and cortex in the right panel. BDNF levels were only increased in progesterone administered wild-type mice in the hippocampus. The bottom panel represents maximum muscimol binding ( $n=5 /$ group) in the hippocampus in the left panel, and cortex in the right panel. Both

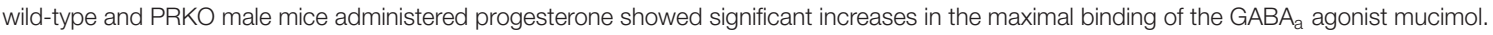


concomitant with increased levels of allopregnanolone in the hippocampus (29). Progesterone can also have beneficial effects in other behaviors. For example, progesterone has beneficial effects for sexual behavior, motivation, anxiety, response to drugs of abuse (24) and also, depressive-like behaviors (54). Thus, progesterone exerts beneficial effects on cognition as well as other behaviors.

Progesterone can also have neuroprotective effects in the brain. The neuroprotective effects of progesterone have been demonstrated in rodent models of neurodegeneration (67), brain ischemia/stroke (68-71), and traumatic brain injury (TBI) (72-78). Moreover, progesterone limits the extent of tissue damage and the impairment of motor functions in an animal model of stroke (77). Furthermore, progesterone has neuroprotective and cognitive enhancing effects however progesterone also can have beneficial effects in other disorders (i.e., Alzheimer's, Parkinson etc.). Thus, progesterone can have neuroprotective and cognition enhancing, which support the purpose of such investigations.

BDNF levels were increased in the hippocampus with progesterone administration to wild-type, but not PRKO, mice compared to vehicle administration. As such, these findings add and extend the literature on interactions between progesterone and growth factors. In support, progesterone failed to elicit an increase in BDNF in PRKO mice but induced an increase in BDNF levels of wild-type mice (79). This evidence has suggested that classical intracellular/nuclear PR would be the principle mediator of the effects of progesterone on BDNF expression because this effect was inhibited by the pharmacological inhibitor of PRs, Mifepristone, and was lost in PRKO mice (79). In addition, levels of BDNF in the cortex and hippocampus were lowest among mice administered a synthetic progestin, medroxyprogesterone acetate, that does not act like progesterone to induce allopregnanolone synthesis, suggesting a downstream role of this growth factor $(12,79)$. Indeed, progesterone increased BDNF levels; however, this may only be possible by way of its metabolite, allopregnanolone. Furthermore, among young cycling rodents, manipulation of allopregnanolone synthesis in the midbrain alters expression of BDNF in the hippocampus (61). Others have noted that allopregnanolone alters BDNF expression in other limbic structures, such as the amygdala and hypothalamus, in addition to the hippocampus (80). Together, production of allopregnanolone in the hippocampus may be required for progesterone's mnemonic effects to increase BDNF levels.

In the present study, allopregnanolone levels were increased in the hippocampus and cortex of PRKO and wild-type mice. This may be due to increased activity of the stress axis, which can interact to alter circulating and brain levels of steroids (e.g., neurosteroids), particularly among mice. Though PRKO mice had increased levels of allopregnanolone, this was not associated with increased BDNF levels, which support the notion that PRs may not be involved for cognitive improvements with progesterone administration. It must be noted that levels of allopregnanolone and progesterone are very low in male mice, but they are not completely absent. This may be because there can be de novo synthesis of allopregnanolone in the brain itself, in addition to metabolism of circulating progesterone. Indeed, it may be that these levels of allopregnanolone were produced via actions in the hippocampus, cortex and/or other regions in this circuit involved in the behaviors observed. Another consideration is that the behavioral effects of PRKO mice may be less related to effects on production of allopregnanolone, or even other steroids that can be derived in the periphery or brain (progesterone), but may relate more to different rates of clearance of neuroactive steroids. Moreover, these effects may be related to increased rates of progesterone conversion to allopregnanolone, which is known to increase following environmental stressors (e.g., cold water swim, restraint) as well as social challenges (e.g., mating) and mitigates stress responding [reviewed in $(24,81,82)]$. Furthermore, this may explain the difference that was shown in the water maze task (latency to find the platform). The water maze requires a high degree of physical activity (swimming), remembering where a hidden escape platform is located in the pool, and a probe trial. Although this was not directly tested in the present study, the water maze task may be associated with an increased stress response in PRKO mice, which could lead to higher levels of allopregnanolone in circulation among both progesterone and vehicle administered mice. Thus, clearance of neurosteriods and/or stress responsiveness may play an important role in allopregnanolone production. Further investigation of this is substantiated.

\section{CONCLUSION}

In conclusion, progesterone can have beneficial effects for cognitive performance among males. An important piece to this story may be progesterone's metabolite, allopregnanolone, and effects on $\mathrm{BDNF}$ levels in the hippocampus or $\mathrm{GABA}_{\mathrm{A}}$ receptors in the cortex.

\section{IMPLICATIONS}

Progesterone and its neuroactive metabolite, allopregnanolone, cognitive effects' among males is not well-understood and is addressed in this study. Progesterone ( $4 \mathrm{mg} / \mathrm{kg}$, or oil vehicle SC) administered post-training in hippocampus and/or cortex tasks to wild type or mice lacking functional nuclear PRs. In the water maze task, wild-type mice tended to outperform PRKO mice. Progesterone enhanced performance of irrespective of genotype in the water maze, object learning and T-maze. Progesterone, but not vehicle, increased progesterone and allopregnanolone levels of wild-type and PRKO mice; albeit, PRKO mice had higher allopregnanolone levels than did wild-type in the hippocampus and cortex. Wild-type mice administered progesterone, but not vehicle, had increased BDNF levels in the hippocampus compared to PRKOs. Thus, male mice can be responsive to progesterone for learning/memory, and such effects do not require PRs, but may be associated with allopregnanolone and BDNF levels in the hippocampus or $\mathrm{GABA}_{\mathrm{A}}$ activity in the cortex. 


\section{DATA AVAILABILITY STATEMENT}

The raw data supporting the conclusions of this article will be made available by the authors, without undue reservation.

\section{ETHICS STATEMENT}

The animal study was reviewed and approved by Institutional Animal Care and Use Committee.

\section{AUTHOR CONTRIBUTIONS}

AW: data production. VL: formal analysis. CF: funding acquisition, supervision, concept, and original draft. All authors contributed to the article and approved the submitted version.

\section{REFERENCES}

1. Blaustein JD. Neuroendocrine regulation of feminine sexual behavior: lessons from rodent models and thoughts about humans. Annu Rev Psychol. (2008) 59:93-118. doi: 10.1146/annurev.psych.59.103006.093556

2. Priest CA, Pfaff DW. Actions of sex steroids on behaviours beyond reproductive reflexes. CIBA Found Symp. (1995) 191:74-84. doi: 10.1002/9780470514757.ch5

3. Frye CA. Neurosteroids' effects and mechanisms for social, cognitive, emotional, and physical functions. Psychoneuroendocrinology. (2009) 34 (Suppl. 1):S143-61. doi: 10.1016/j.psyneuen.2009.07.005

4. Fadda P, Fratta W. Stress-induced sleep deprivation modifies corticotropin releasing factor (CRF) levels and CRF binding in rat brain and pituitary. Pharmacol Res. (1997) 35:443-6. doi: 10.1006/phrs.1997.0155

5. Kalra PS, Kalra SP. Circadian periodicities of serum androgens, progesterone, gonadotropins and luteinizing hormone-releasing hormone in male rats: the effects of hypothalamic differentiation, castration and adrenalectomy. Endocrinology. (1997) 101:1821-7. doi: 10.1210/endo-101-6-1821

6. Andersen ML, Bignotto M, Machado RB, Tufik S. Different stress modalities result in distinct steroid hormone responses by male rats. Braz J Med Biol Res. (2004) 37:791-7. doi: 10.1590/S0100-879X2004000600003

7. Auger CJ, Vanzo RJ. Progesterone treatment of adult male rats suppresses arginine vasopressin expression in the bed nucleus of the stria terminalis and the centromedial amygdala. J Neuroendocrinol. (2006) 18:187-94. doi: 10.1111/j.1365-2826.2005.01400.x

8. Weisz J, Ward IL. Plasma testosterone and progesterone titers of pregnant rats, their male and female fetuses, and neonatal offspring. Endocrinology. (1980) 106:306-16. doi: 10.1210/endo-106-1-306

9. Bian C, Zhang D, Guo Q, Cai W, Zhang J. Localization and sex-difference of steroid receptor coactivator-1 immunoreactivities in the brain of adult female and male mice. Steroids. (2011) 76:269-79. doi: 10.1016/j.steroids.2010.11.009

10. Si D, Wang H, Wang Q, Zhang C, Sun J, Wang Z, et al. Progesterone treatment improves cognitive outcome following experimental traumatic brain injury in rats. Neurosci Lett. (2013) 11:18-23. doi: 10.1016/j.neulet.2013.07.052

11. Peterson TC, Anderson GD, Kantor ED, Hoane MR. A comparison of the effects of nicotinamide and progesterone on functional recovery of cognitive behavior following cortical contusion injury in the rat. J Neurotrauma. (2012) 29:2823-30. doi: 10.1089/neu.2012.2471

12. Frye CA, Koonce CJ, Walf AA. Progesterone, compared to medroxyprogesterone acetate, to $\mathrm{C} 57 \mathrm{BL} / 6$, but not $5 \alpha$-reductase mutant, mice enhances object recognition and placement memory and is associated with higher BDNF levels in the hippocampus and cortex. Neurosci Lett. (2013) 551:53-7. doi: 10.1016/j.neulet.2013.07.002

13. Frye CA, Walf AA. Progesterone enhances performance of aged mice in cortical or hippocampal tasks. Neurosci Lett. (2008) 437:116-20. doi: 10.1016/j.neulet.2008.04.004

\section{FUNDING}

Research herein was supported in part by grants National Institute of Mental Health (MH 06769801, RMH067698B) and the National Institute of General Medical Sciences of the National Institutes of Health (P20GM103395). The content is solely the responsibility of the authors and does not necessarily represent the official views of the National Institutes of Health. Assistance on the studies described herein provided by members of the laboratory, past and present, is greatly appreciated.

\section{ACKNOWLEDGMENTS}

Whitney Johnson, Carolyn Koonce, and other lab members also assisted in this project.

14. Frye CA, Walf AA. Progesterone to ovariectomized mice enhances cognitive performance in the spontaneous alternation, object recognition, but not placement, water maze, and contextual and cued conditioned fear tasks. Neurobiol Learn Mem. (2008) 90:171-7. doi: 10.1016/j.nlm.2008.03.005

15. McEchron MD, Cheng AY, Gilmartin MR. Trace fear conditioning is reduced in the aging rat. Neurobiol Learn Mem. (2004) 82:71-6. doi: 10.1016/j.nlm.2004.06.002

16. Li X, Lonard DM, O'Malley BW. A contemporary understanding of progesterone receptor function. Mech Ageing Dev. (2004) 125:669-78. doi: 10.1016/j.mad.2004.04.007

17. Hagihara K, Hirata S, Osada T, Hirai M, Kato J. Expression of progesterone receptor in the neonatal rat brain cortex: detection of its mRNA using reverse transcription-polymerase chain reaction. J Steroid Biochem Mol Biol. (1992) 41:637-40. doi: 10.1016/0960-0760(92)90396-Z

18. Blaustein JD, Wade GN. Progestin binding by brain and pituitary cell nuclei and female rat sexual behavior. Brain Res. (1978) 140:360-7. doi: 10.1016/0006-8993(78)90469-9

19. Frye CA. Neurosteroids-from basic research to clinical perspectives. In: Rubin RT, Pfaff DW, editors. Hormones/Behavior Relations of Clinical Importance. San Diego: Academic Press (2009). p. 395-416.

20. Iswari S, Colas AE, Karavolas HJ. Binding of 5 alpha-dihydroprogesterone and other progestins to female rat anterior pituitary nuclear extracts. Steroids. (1986) 47:189-203. doi: 10.1016/0039-128X(86)90088-7

21. Majewska MD, Harrison NL, Schwartz RD, Barker JL, Paul SM. Steroid hormone metabolites are barbiturate-like modulators of the GABA receptor. Science. (1986) 232:1004-7. doi: 10.1126/science.2422758

22. Farr SA, Flood JF, Scherrer JF, Kaiser FE, Taylor GT, Morley JE. Effect of ovarian steroids on footshock avoidance learning and retention in female mice. Physiol Behav. (1995) 58:715-23. doi: 10.1016/0031-9384(95)00124-2

23. Finn DA, Phillips TJ, Okorn DM, Chester JA, Cunningham CL. Rewarding effect of the neuroactive steroid 3 alpha-hydroxy-5 alphapregnan-20-one in mice. Pharmacol Biochem Behav. (1997) 56:261-4. doi: 10.1016/S0091-3057(96)00218-3

24. Frye CA. Progestins influence motivation, reward, conditioning, stress, and/or response to drugs of abuse. Pharmacol Biochem Behav. (2007) 86:209-19. doi: 10.1016/j.pbb.2006.07.033

25. Frye CA, Sturgis JD. Neurosteroids affect spatial/reference, working, and long-term memory of female rats. Neurobiol Learn Mem. (1995) 64:83-96. doi: 10.1006/nlme.1995.1046

26. Manshio DT, Gershbein LL. Avoidance and poke behavior in rats after gonadectomy and hormanal treatment. Res Commun Chem Pathol Pharmacol. (1975) 12:473-80

27. Walf AA, Rhodes ME, Frye CA. Ovarian steroids enhance object recognition in naturally cycling and ovariectomized, hormone-primed rats. Neurobiol Learn Mem. (2006) 86:35-46. doi: 10.1016/j.nlm.200 6.01 .004 
28. Lydon JP, DeMayo FJ, Conneely OM, O'Malley BW. Reproductive phenotpes of the progesterone receptor null mutant mouse. J Steroid Biochem Mol Biol. (1996) 56:67-77. doi: 10.1016/0960-0760(95)00254-5

29. Frye CA, Sumida K, Dudek BC, Harney JP, Lydon JP, O’Malley BW, et al. Progesterone's effects to reduce anxiety behavior of aged mice do not require actions via intracellular progestin receptors. Psychopharmacology. (2006) 186:312-22. doi: 10.1007/s00213-006-0309-3

30. Frye CA, Walf AA. Progesterone enhances performance of aged mice in cortical or hippocampal tasks. Neurosci Lett. (2010) 472:38-42. doi: 10.1016/j.neulet.2010.01.051

31. Causing CG, Gloster A, Aloyz R, Bamji SX, Chang E, Fawcett J, et al. Synaptic innervation density is regulated by neuron-derived BDNF. Neuron. (1997) 18:257-67. doi: 10.1016/S0896-6273(00)80266-4

32. Pruginin-Bluger M, Shelton DL, Kalcheim C. A paracrine effect for neuronderived BDNF in development of dorsal root ganglia: stimulation of Schwann cell myelin protein expression by glial cells. Mech Dev. (1997) 61:99-111. doi: 10.1016/S0925-4773(96)00623-5

33. Pluchino N, Russo M, Santoro AN, Litta P, Cela V, Genazzani AR. Steroids hormones and BDNF. Neuroscience. (2013) 3:271-9. doi: 10.1016/j.neuroscience.2013.01.025

34. Singh $\mathrm{M}$, Su C. Progesterone, brain-derived neurotrophic factor and neuroprotection n. Neuroscience. (2013) 239:84-91. doi: 10.1016/j.neuroscience.2012.09.056

35. Murer MG, Yan Q, Raisman-Vozari R. Brain-derived neurotrophic factor in the control human brain, and in Alzheimer's disease and Parkinson's disease. Prog Neurobiol. (2001) 63:71-124. doi: 10.1016/S0301-0082(00)00014-9

36. Ferrer I, Marín C, Rey MJ, Ribalta T, Goutan E, Blanco R, et al. BDNF and full-length and truncated TrkB expression in Alzheimer disease. Implications in therapeutic strategies. J Neuropathol Exp Neurol. (1999) 58:729-39. doi: 10.1097/00005072-199907000-00007

37. Tapia-Arancibia L, Aliaga E, Silhol M, Arancibia S. New insights into brain BDNF function in normal aging and Alzheimer disease. Brain Res Rev. (2008) 59:201-20. doi: 10.1016/j.brainresrev.2008.07.007

38. Zuccato C, Cattaneo E. Brain-derived neurotrophic factor in neurodegenerative diseases. Nat Rev Neurol. (2009) 5:311-22. doi: 10.1038/nrneurol.2009.54

39. Connor B, Young D, Yan Q, Faull RL, Synek B, Dragunow M. Brain-derived neurotrophic factor is reduced in Alzheimer's disease. Brain Res Mol Brain Res. (1997) 49:71-81. doi: 10.1016/S0169-328X(97)00125-3

40. Hock C, Heese K, Hulette C, Rosenberg C, Otten U. Region-specific neurotrophin imbalances in Alzheimer disease: decreased levels of brainderived neurotrophic factor and increased levels of nerve growth factor in hippocampus and cortical areas. Arch Neurol. (2000) 57:846-51. doi: 10.1001/archneur.57.6.846

41. Karege F, Perret G, Bondolfi G, Schwald M, Bertschy G, Aubry JM. Decreased serum brain-derived neurotrophic factor levels in major depressed patients. Psychiatry Res. (2002) 109:143-8. doi: 10.1016/S0165-1781(02)00005-7

42. Mogi M, Togari A, Kondo T, Mizuno Y, Komure O, Kuno S, et al. Brainderived growth factor and nerve growth factor concentrations are decreased in the substantia nigra in Parkinson's disease. Neurosci Lett. (1999) 270:45-8. doi: 10.1016/S0304-3940(99)00463-2

43. Parain K, Murer MG, Yan Q, Faucheux B, Agid Y, Hirsch E, et al. Reduced expression of brain-derived neurotrophic factor protein in Parkinson's disease substantia nigra. Neuroreport. (1999) 10:557-61. doi: 10.1097/00001756-199902250-00021

44. Soontornniyomkij V, Wang G, Pittman CA, Hamilton RL, Wiley CA, Achim CL. Absence of brain-derived neurotrophic factor and trkB receptor immunoreactivity in glia of Alzheimer's disease. Acta Neuropathol. (1999) 98:345-8. doi: 10.1007/s004010051092

45. von Bohlen und Halbach O, Minichiello L, Unsicker K. Haploinsufficiency for trkB and trkC receptors induces cell loss and accumulation of $\alpha$-synuclein in the substantia nigra. FASEB J. (2005) 19:1740-2. doi: 10.1096/fj.05-3845fje

46. Komulainen , Pedersen $M$, Hänninen T, Bruunsgaard $H$, Lakka TA, Kivipelto M, et al. BDNF is a novel marker of cognitive function in ageing women: the DR's EXTRA Study. Neurobiol Learn Mem. (2008) 90:596-603. doi: 10.1016/j.nlm.2008.07.014

47. Lindvall O, Kokaia Z, Bengzon J, Elmér E, Kokaia M. Neurotrophins and brain insults. Trends Neurosci. (1994) 17:490-6. doi: 10.1016/0166-2236(94)90139-2
48. Aguirre CC, Baudry M. Progesterone reverses 17beta-estradiol-mediated neuroprotection and BDNF induction in cultured hippocampal slices. Eur J Neurosci. (2009) 29:447-54. doi: 10.1111/j.1460-9568.2008.06591.x

49. Gibbs RB. Levels of trkA and BDNF mRNA, but not NGF mRNA, fluctuate across the estrous cycle and increase in response to acute hormone replacement. Brain Res. (1998) 787:259-68. doi: 10.1016/S0006-8993(97)01511-4

50. González SL, Labombarda F, González Deniselle MC, Guennoun R, Schumacher M, De Nicola AF. Progesterone up-regulates neuronal brain-derived neurotrophic factor expression in the injured spinal cord. Neuroscience. (2004) 125:605-14. doi: 10.1016/j.neuroscience.2004.02.024

51. Gonzalez Deniselle MC, Garay L, Gonzalez S, Saravia F, Labombarda F, Guennoun R, et al. Progesterone modulates brain-derived neurotrophic factor and choline acetyltransferase in degenerating Wobbler motoneurons. Exp Neurol. (2007) 203:406-14. doi: 10.1016/j.expneurol.2006.08.019

52. Kaur P, Jodhka PK, Underwood WA, Bowles CA, de Fiebre NC, de Fiebre CM, et al. Progesterone increases brain derived neuroptrophic factor expression and protects against glutamate toxicity in a mitogen-activated protein kinase- and phosphoinositide-3 kinase-dependent manner in cerebral cortical explants. J Neurosci Res. (2007) 85:2441-9. doi: 10.1002/jnr.21370

53. Singh M, Meyer EM, Simpkins JW. The effect of ovariectomy and estradiol replacement on brain-derived neurotrophic factor messenger ribonucleic acid expression in cortical and hippocampal brain regions of female Sprague-Dawley rats. Endocrinology. (1995) 136:2320-4. doi: $10.1210 /$ endo.136.5.7720680

54. Frye CA. Progesterone attenuates depressive behavior of younger and older adult C57/BL6, wildtype, and progesterone receptor knockout mice. Pharmacol Biochem Behav. (2011) 99:525-31. doi: 10.1016/j.pbb.2011.05.024

55. Lydon JP, DeMayo FJ, Funk CR, Mani SK, Hughes AR Jr, Montgomery CA et al. Mice lacking progesterone receptors exhibit pleiotropic reproductive abnormalities. Genes Dev. (1995) 9:2266-78. doi: 10.1101/gad.9.18.2266

56. Sambrook J, Fritsch EF, Maniatis T. Molecular Cloning: A Laboratory Manual. New York, NY: Cold Spring Harbor Laboratory Press (1989).

57. Frye CA, Koonce CJ, Walf AA. Mnemonic effects of progesterone to mice require formation of 3alpha,5alpha-THP. Neuroreport. (2010) 21:590-5. doi: 10.1097/WNR.0b013e32833a7e14

58. Walf AA, Frye CA. Object Recognition - The role of hormones throughout the lifespan. In: Cao TP, editor. Object Recognition. InTech (2011).

59. Spowart-Manning L, van der Staay FJ. The T-maze continuous alternation task for assessing the effects of putative cognition enhancers in the mouse. Behav Brain Res. (2004) 151:37-46. doi: 10.1016/j.bbr.2003.08.004

60. Frye CA, Rhodes ME, Dudek B. Estradiol to aged female or male mice improves learning in inhibitory avoidance and water maze tasks. Brain Res. (2005) 1036:101-8. doi: 10.1016/j.brainres.2004.12.014

61. Frye CA, Koonce CJ, Walf AA. Involvement of pregnane xenobiotic receptor in mating-induced allopregnanolone formation in the midbrain and hippocampus and brain-derived neurotrophic factor in the hippocampus among female rats. Psychopharmacology. (2014) 231:3375-90. doi: 10.1007/s00213-014-3569-3

62. McEwen BS. Endocrine effects on the brain and their relationship to behavior. Basic Neurochem. (2012) 8:945-62. doi: 10.1016/B978-0-12-374947-5.00055-9

63. Frye CA, Duncan JE, Basham M, Erskine MS. Behavioral effects of 3a-androstanediol II: Hypothalamic and preoptic area actions via a GABAergic mechanism. Behav Brain Res. (1996) 79:119-30. doi: 10.1016/0166-4328(96)00005-8

64. Lewis MC, Orr PT, Frick KM. Acute progesterone enhances spatial and object memory in aged female C57BL/6 mice. Hormones Behav. (2008) 54:455-62.

65. Mani SK, Allen JM, Clark JH, Blaustein JD, O’Malley BW. Steroid hormoneand neurotransmitter-induced rat sexual behavior: addendum. Science. (1995) 268:1833. doi: 10.1126/science.7604251

66. Mani SK, Allen JM, Lydon JP, Mulac-Jericevic B, Blaustein JD, DeMayo FJ, et al. Dopamine requires the unoccupied progesterone receptor to induce sexual behavior in mice. Mol Endocrinol. (1996) 10:1728-37. doi: 10.1210/mend.10.12.8961281

67. Vongher JM, Frye CA. Progesterone in conjunction with estradio has neuroprotective effects in an animal model of neurodegeneration. Pharmacol Biochem Behav. (1999) 64:777-85. doi: 10.1016/S0091-3057(99)0 0140-9 
68. Cervantes M, González-Vidal MD, Ruelas R, Escobar A, Moralí G. Neuroprotective effects of progesterone on damage elicited by acute global cerebral ischemia in neurons of the caudate nucleus. Arch Med Res. (2002) 33:6-14. doi: 10.1016/S0188-4409(01)00347-2

69. Sayeed I, Wali B, Stein DG. Progesterone inhibits ischemic brain injury in a rat model of permanent middle cerebral artery occlusion. Restor Neurol Neurosci. (2007) 25:151-9.

70. Gibson CL, Coomber B, Rathbone J. Is progesterone a candidate neuroprotective factor for treatment following ischemic stroke? Neuroscientist. (2009) 15:324-32. doi: 10.1177/1073858409333069

71. Liu A, Margaill I, Zhang S, Labombarda F, Coqueran B, Delespierre B, et al. Progesterone receptors: a key for neuroprotection in experimental stroke. Endocrinology. (2012) 153:3747-57. doi: 10.1210/en.2012-1138

72. Stein DG. Brain damage, sex hormones and recovery: a new role for progesterone and estrogen? Trends Neurosci. (2001) 24:386-91. doi: 10.1016/S0166-2236(00)01821-X

73. Stein DG, Sayeed I. Is progesterone worth consideration as a treatment for brain injury? AJR Am J Roentgenol. (2010) 194:20-22. doi: 10.2214/AJR.09.3407

74. Schumacher M, Guennoun R, Stein DG, De Nicola AF. Progesterone: therapeutic opportunities for neuroprotection and myelin repair. Pharmacol Ther. (2007) 116:77-106. doi: 10.1016/j.pharmthera.2007.06.001

75. Brinton RD, Thompson RF, Foy MR, Baudry M, Wang J, Finch CE, et al. Progesterone receptors: form and function in brain. Front Neuroendocrinol. (2008) 29:313-39. doi: 10.1016/j.yfrne.2008.02.001

76. Gibson CL, Gray LJ, Bath PM, Murphy SP. Progesterone for the treatment of experimental brain injury; a systematic review. Brain. (2008) 131(Pt 2):31828. doi: 10.1093/brain/awm183

77. Stein DG. Progesterone exerts neuroprotective effects after brain injury. Brain Res Rev. (2008) 57:386-97. doi: 10.1016/j.brainresrev.2007.06.012
78. Stein DG, Wright DW. Progesterone in the clinical treatment of acute traumatic brain injury. Expert Opin Investig Drugs. (2010) 19:847-57. doi: 10.1517/13543784.2010.489549

79. Jodhka PK, Kaur P, Underwood W, Lydon JP, Singh M. The differences in neuroprotective efficacy of progesterone and medroxyprogesterone acetate correlate with their effects on brain-derived neurotrophic factor expression. Endocrinology. (2009) 150:3162-8. doi: 10.1210/en.200 8-1247

80. Naert G, Maurice T, Tapia-Arancibia L, Givalois L. Neuroactive steroids modulate HPA axis activity and cerebral brain-derived neurotrophic factor (BDNF) protein levels in adult male rats. Psychoneuroendocrinology. (2007) 32:1062-78. doi: 10.1016/j.psyneuen.2007.09.002

81. Maguire J, Mody I. Neurosteroid synthesis-mediated regulation of GABA(A) receptors: relevance to the ovarian cycle and stress. J Neurosci. (2007) 27:215562. doi: 10.1523/JNEUROSCI.4945-06.2007

82. Sarkar J, Wakefield S, MacKenzie G, Moss SJ, Maguire J. McEwen Neurosteroidogenesis is required for the physiological response to stress: role of neurosteroid-sensitive GABAA receptors. J Neurosci. (2011) 31:18198-210. doi: 10.1523/JNEUROSCI.2560-11.2011

Conflict of Interest: The authors declare that the research was conducted in the absence of any commercial or financial relationships that could be construed as a potential conflict of interest.

Copyright (c) 2021 Frye, Lembo and Walf. This is an open-access article distributed under the terms of the Creative Commons Attribution License (CC BY). The use, distribution or reproduction in other forums is permitted, provided the original author(s) and the copyright owner(s) are credited and that the original publication in this journal is cited, in accordance with accepted academic practice. No use, distribution or reproduction is permitted which does not comply with these terms. 